\title{
Agreement with evidence for tissue Plasminogen Activator use among emergency physicians: a cross-sectional survey
}

\author{
Alice M Grady ${ }^{1 *}$, Jamie Bryant ${ }^{1}$, Mariko L Carey ${ }^{1}$, Christine L Paul ${ }^{1}$, Rob W Sanson-Fisher ${ }^{1}$ \\ and Christopher R Levi ${ }^{2,3}$
}

\begin{abstract}
Background: Emergency department staff play a crucial role in the triage of stroke patients and therefore the capacity to deliver time-dependent treatments such as tissue Plasminogen Activator. This study aimed to identify among emergency physicians, (1) rates of agreement with evidence supporting tissue Plasminogen Activator use in acute stroke care; and (2) individual and hospital factors associated with high agreement with evidence supporting tissue Plasminogen Activator use.

Methods: Australian fellows and trainees of the Australasian College for Emergency Medicine were invited to complete an online cross-sectional survey assessing perceptions of tissue Plasminogen Activator use in acute stroke. Demographic and hospital characteristics were also collected.

Results: 429 Australasian College for Emergency Medicine members responded (13\% response rate). Almost half (47.2\%) did not agree with any statements regarding the benefits of tissue Plasminogen Activator use for acute stroke. Perceived routine administration of tissue Plasminogen Activator by the head of respondents' emergency department was significantly associated with high agreement with the evidence supporting tissue Plasminogen Activator use in acute stroke.

Conclusions: Agreement with evidence supporting tissue Plasminogen Activator use in acute stroke is not high among responding Australian emergency physicians. In order for tissue Plasminogen Activator treatment to become widely accepted and adopted in emergency settings, beliefs and attitudes towards treatment need to be in accordance with clinical practice guidelines.
\end{abstract}

Keywords: Emergency medicine, Stroke, Stroke care, Thrombolysis, Treatment

\section{Background}

\section{Stroke and tissue Plasminogen Activator (tPA)}

Globally, stroke is the third most common cause of disability-adjusted life years (DALYs) [1]. Thrombolytic therapy using intravenous tPA is both an effective [2] and cost-effective [3] treatment in eligible acute ischemic stroke patients, significantly improving the chance of a good recovery when used in accordance with strict

\footnotetext{
*Correspondence: Alice.Grady@newcastle.edu.au

1 Priority Research Centre for Health Behaviour, Hunter Medical Research Institute (HMRI), University of Newcastle, Callaghan, NSW 2308, Australia Full list of author information is available at the end of the article
}

protocols [4]. However, tPA carries risk of haemorrhage [4] and can only be administered within $4.5 \mathrm{~h}$ of stroke onset [5], which provides challenges to its widespread use. Currently $53 \%$ of Australian hospitals report offering [6], and 7\% of patients receive, tPA treatment [7]. Rates of use are lower in other countries; $5 \%$ of stroke patients receive tPA in the United Kingdom (UK) [8] and 2.4\% of ischemic stroke patients receive tPA in the United States (US) [9].

\section{Physicians' attitudes towards tPA}

Emergency department (ED) staff play a crucial role in the triage and in-hospital care of stroke patients. Timely 
assessment and referral in line with clinical guidelines is particularly important for stroke patients eligible for tPA treatment. Emergency physicians may be responsible for the treatment of stroke patients in hospitals without dedicated specialists.

Risks associated with tPA in acute stroke may contribute to physician uncertainty in administering treatment [4]. A 2005 survey of US emergency physicians indicated $40 \%$ were unlikely to administer tPA for acute stroke in an ideal setting [10]. Attitudes may be shifting with a 2010 survey showing that $17 \%$ of emergency physicians were uncertain or unlikely to administer tPA in an ideal setting [11]. However, the latter survey was limited to emergency physicians from community hospitals participating in a cluster randomised controlled trial [11]. A 2004 New Zealand (NZ) survey indicated $73 \%$ of physicians rarely or never administer tPA treatment [12]. This sample included a range of health-care providers, limiting the generalisability of findings to the emergency context.

A discrepancy between the optimum hospital environment outlined in clinical guidelines and the actual settings in which tPA treatment is administered may also contribute to implementation challenges $[6,13]$. Furthermore, in 2013, Australia's National Stroke Foundation (NSF) reported $24 \%$ of hospitals without a stroke care unit (SCU) provide thrombolysis [6].

Emergency physicians' perceptions of the evidence in support of tPA use in stroke have not been examined recently. Perceptions may have altered as a consequence of public media campaigns [F.A.S.T (Face, Arm, Speech, Time) campaigns launched by NSF, American Heart Association (AHA) and American Stroke Association (ASA), and the UK's Stroke Association], publicised debate regarding potential benefits and risks of tPA treatment [14], and release of clinical guidelines with an increased time-frame for treatment $[5,15]$. As such, an examination of whether attitudes of emergency health-care providers are supportive of tPA use in acute stroke, or whether they might be one of the factors limiting tPA rates is required. The study successfully identified, among a sample of emergency physicians, (1) rates of agreement with evidence supporting tPA use in acute stroke care; and (2) individual and hospital factors associated with high agreement with evidence supporting tPA use.

\section{Methods}

\section{Setting}

An online cross-sectional survey of emergency physicians in Australia was conducted July-August 2012. The University of Newcastle's Human Research Ethics Committee and the Australasian College for Emergency
Medicine (ACEM) Scientific Committee approved the study.

\section{Participants}

Australian trainees and fellows registered with ACEM were invited to participate. All emergency physician trainees and fellows within Australia are registered with ACEM, providing access to a representative sample of this specialty group. Fellows of ACEM have completed a minimum of 7 years post-graduate medical training, and participate in ongoing professional training to maintain this title.

\section{Procedure}

Potential participants were sent an email from ACEM containing an information statement and link to the survey. A reminder email was sent two weeks following initial correspondence. Completion of the survey was taken as implied consent.

\section{Measures}

Responders completed an online survey administered via Survey Monkey (see Additional file 1). Measures were developed based on recommended hospital facilities and evidence supporting tPA use according to NSF's Clinical Guidelines for Stroke Management [5]. Items were reviewed by two stroke specialists and two emergency physicians at a tertiary hospital to ensure they reflected findings from published literature. The survey was then pilot tested with five health behaviour researchers who reviewed the items to ensure comprehension. Items included:

\section{Physician characteristics}

Age; gender; role within the hospital; number of years worked in emergency care; and role in stroke care. Deidentified data on all fellows and trainees (gender and location) was obtained from ACEM to assess response bias.

\section{Hospital characteristics}

State; whether arrangements for pre-hospital notification from ambulance are in place; number of ischemic stroke patients presenting to ED per fortnight; an estimate of the proportion of stroke patients referred to an SCU or neurology department; presence of an SCU; presence of an intensive care unit (ICU); whether advanced imaging facilities are available; whether the hospital provides tPA treatment; an estimate of the proportion of ischemic stroke patients receiving tPA treatment; an estimate of the proportion of emergency physicians giving tPA treatment; and whether the head of ED routinely provides tPA treatment. 


\section{Perception of tPA use in acute stroke}

Participants were presented with six items reflecting published literature limited to the benefits of tPA use in acute stroke, and two items about their concerns using tPA treatment. Participants rated how much they agreed or disagreed with each item on a five point likert scale (strongly disagree [1] to strongly agree [5]). Participants were also asked 'What would influence your views on the use of tPA in acute stroke?' Response options included 'Guidance from a professional colleague, 'Guidance from an expert in the use of tPA for acute stroke', 'Additional clinical trials of tPA', 'Research conducted by ED staff', and 'Other'.

\section{Data analysis}

Descriptive statistics were calculated to describe the demographic and workplace characteristics of responders, and the survey responses. Characteristics of responders and grouped de-identified data on non-responders were compared using $\chi^{2}$ tests.

Each respondent received an accumulated score of 0-6 based on their level of agreement with items. For each item the responses 'strongly agree' or 'agree' were given a score of 1 and all remaining responses a score of 0 . "High agreement" was defined as an accumulated score of $\geq 4$; "Low agreement" was a score of $1-3$; and "No agreement" was a score of 0 . The association between all physician and hospital characteristics on the level of agreement ("High agreement" vs "Low/No agreement") with evidence for tPA use in acute stroke was evaluated separately using logistic regression. All variables identified as significant at a p-value of 0.2 or less were included in a stepwise logistic regression analysis. For the final multiple logistic regression, variables that met a significance level of $\mathrm{p}<0.05$ were included in the model. Missing data were excluded.

\section{Results}

The study had 55 and $52 \%$ power at the $5 \%$ significance level to detect a $0.55 / 0.45$ difference in proportions of respondents who agree/disagree with each item.

\section{Response rate and physician characteristics}

Of the 3,280 ACEM members invited to participate, 429 responded (response rate $=13 \%$ ). Results of chi-square analyses indicated males $\left[\mathrm{X}^{2}(1, \mathrm{n}=3,278)=6.54\right.$, $\mathrm{p}=0.01]$, and respondents working in Victoria $\left[\mathrm{X}^{2}(7\right.$, $\mathrm{n}=3,280)=33.10, \mathrm{p}<0.01$ ] were more likely to participate. Table 1 shows characteristics of responders and non-responders. Of those responsible for deciding which patients receive tPA, the median proportion of eligible patients perceived to be treated with tPA was $15 \%$.
Table 1 Demographics and characteristics of responders $(n=370)$ and non-responders $(n=2910)$

\begin{tabular}{|c|c|c|}
\hline & Responders & Non-responders \\
\hline Characteristic & Mean (SD) & Mean (SD) \\
\hline \multirow[t]{2}{*}{ Age } & $41.1(8.2)$ & NA \\
\hline & n (\%) & n (\%) \\
\hline Male & $256(69.2)$ & $1814(62.4)$ \\
\hline $\begin{array}{l}\text { Years worked in emergency } \\
\text { care }\end{array}$ & & NA \\
\hline$\leq 5$ years & $59(15.9)$ & \\
\hline $5-10$ years & $92(24.9)$ & \\
\hline $11-15$ years & $90(24.3)$ & \\
\hline$\geq 16$ years & $129(34.9)$ & \\
\hline Role within the hospital* & & NA \\
\hline Emergency physician & $229(63.8)$ & \\
\hline Emergency physician trainee & $122(34.0)$ & \\
\hline Other & $8(2.2)$ & \\
\hline \multicolumn{3}{|l|}{ Location* } \\
\hline New South Wales (NSW) & $95(26.5)$ & $809(27.7)$ \\
\hline Victoria (VIC) & $108(30.1)$ & $715(24.5)$ \\
\hline Queensland (QLD) & $72(20.1)$ & $715(24.5)$ \\
\hline South Australia (SA) & $20(5.6)$ & $212(7.3)$ \\
\hline Western Australia (WA) & $27(7.5)$ & $331(11.3)$ \\
\hline Northern Territory (NT) & $10(2.8)$ & $34(1.2)$ \\
\hline $\begin{array}{l}\text { Australian Capital Territory } \\
\text { (ACT) }\end{array}$ & $8(2.2)$ & $44(1.5)$ \\
\hline Tasmania (TAS) & $19(5.3)$ & $61(2.1)$ \\
\hline $\begin{array}{l}\text { Responsible for determining } \\
\text { care provided to stroke } \\
\text { patients* }\end{array}$ & $293(81.6)$ & NA \\
\hline $\begin{array}{l}\text { Decide which patients receive } \\
\text { tPA }^{\dagger}\end{array}$ & $116(41.7)$ & NA \\
\hline
\end{tabular}

Number of observations varies across characteristics due to missing data, multiresponse items, and item applicability.

NA data not available.

${ }^{*} \mathrm{n}=359$.

${ }^{+} \mathrm{n}=278$.

\section{Hospital characteristics}

Table 2 outlines participants' self-reported hospital characteristics. The average number of ischaemic stroke patients seen by the ED every fortnight was 14.1 (SD 12.9). The median proportion of patients referred to a neurology department or SCU from emergency was perceived to be $85 \%$. Of the hospitals that provide tPA treatment to eligible stroke patients, the median proportion of patients perceived to be treated with tPA by emergency physicians was $10 \%$.

\section{Physician agreement with evidence for $\mathrm{PA}$}

Physician agreement with statements for tPA use is provided in Table 3. There were no significant differences 
Table 2 Hospital characteristics of responders $(n=359)$

\begin{tabular}{|c|c|}
\hline Characteristic & $N(\%)$ \\
\hline $\begin{array}{l}\text { Arrangements are in place to receive pre-hospital } \\
\text { notification of stroke patients from the ambulance service }\end{array}$ & $238(66.3)$ \\
\hline The hospital has a dedicated stroke care unit* & $266(74.3)$ \\
\hline The hospital has an intensive care unit* & $338(94.4)$ \\
\hline $\begin{array}{l}\text { The hospital has advanced imaging facilities (perfusion CT } \\
\text { and MRI)* }\end{array}$ & $300(83.8)$ \\
\hline $\begin{array}{l}\text { The hospital provides tPA treatment to eligible ischemic } \\
\text { stroke patients* }\end{array}$ & $278(77.7)$ \\
\hline \multicolumn{2}{|c|}{$\begin{array}{l}\text { The proportion of the emergency physicians at the hospital who rou- } \\
\text { tinely administer tPA treatment for eligible ischemic stroke patients }\end{array}$} \\
\hline None & $184(66.2)$ \\
\hline Less than half & $33(11.9)$ \\
\hline About half & $8(2.9)$ \\
\hline Most & $36(12.9)$ \\
\hline All & $17(6.1)$ \\
\hline \multicolumn{2}{|c|}{$\begin{array}{l}\text { The head of the ED routinely administers tPA treatment for eligible } \\
\text { ischemic stroke patients }{ }^{\dagger}\end{array}$} \\
\hline Yes & $32(11.5)$ \\
\hline No & $173(62.2)$ \\
\hline I do not know & $73(26.3)$ \\
\hline
\end{tabular}

Number of observations varies across characteristics due to missing data and question applicability.

${ }^{*} \mathrm{n}=358$.

$+\mathrm{n}=278$.

in rates of agreement between those who reported their hospital did or did not provide tPA. 19.5\% of respondents had a high level of agreement with these statements, $36.2 \%$ had a low level, and $47.2 \%$ agreed with none of the statements (Figure 1).

$23.7 \%$ of respondents agreed they "have no concerns surrounding the legal implications of tPA use", and 8.9\% agreed they "have no concerns surrounding patient complications of tPA use". When asked "What would influence your views on the use of tPA in acute stroke?" $83.8 \%$ of participants indicated additional trials of tPA,
60.3\% reported research conducted by ED staff, $47.6 \%$ said guidance from an expert in the use of tPA for acute stroke, and $43.8 \%$ indicated guidance from a professional colleague would change their views.

\section{Factors associated with agreement with evidence for tPA}

No physician factors were significantly associated with a high level of agreement with statements supporting tPA use in stroke (Table 4). The perceived routine use of tPA by the head of ED was significantly associated with a high level of agreement with the evidence supporting tPA use (OR 3.87, 95\% CI 1.49-10.04, $\mathrm{p}=0.01$ ) (Table 5).

\section{Discussion}

Even when allowing for the low response rate, study findings suggest a sizeable minority of Australian emergency physician fellows and trainees do not agree with statements supporting use of tPA in the treatment of acute stroke. Consideration of the participating physician and workplace characteristics may suggest that physicians from tertiary hospitals may be over-represented here, therefore, it is likely the majority of results apply to this sub-group.

\section{Physician agreement with evidence for tPA}

As emergency physicians are often the first contact for the in-hospital care of stroke patients, their attitudes towards tPA are a critical factor in the use and non-use of this treatment. Emergency physicians help shape treatment protocols and as such, their perceptions influence the attitudes of others [16]. Given the utility of tPA in significantly reducing disability associated with stroke [5], it is interesting that less than half (39.6\%) of respondents agreed that appropriate use of tPA will improve the odds of independent survival for stroke patients.

Only a small proportion of participants agreed the evidence underpinning tPA use is strong when administered within $4.5 \mathrm{~h}$ of stroke onset (16.8\%), and that the

Table 3 Physician agreement with the evidence for tPA use in acute stroke care $(n=429)$

\begin{tabular}{|c|c|c|c|}
\hline Statement & $\begin{array}{l}\text { Disagree/strongly } \\
\text { disagree } \mathrm{n}(\%)\end{array}$ & $\begin{array}{l}\text { Unsure } \\
\mathrm{n}(\%)\end{array}$ & $\begin{array}{l}\text { Agree/strongly } \\
\text { agree } \mathrm{n}(\%)\end{array}$ \\
\hline \multicolumn{4}{|l|}{ Increasing appropriate use of tPA will: } \\
\hline Save lives & $185(43.1)$ & $155(36.1)$ & $89(20.7)$ \\
\hline Not result in unnecessary adverse events & $267(62.3)$ & $102(23.8)$ & $60(14.0)$ \\
\hline Improve the odds of independent survival for stroke patients & $109(25.4)$ & $150(35.0)$ & $170(39.6)$ \\
\hline \multicolumn{4}{|l|}{ The evidence underpinning tPA use:* } \\
\hline Is strong when administered within $4.5 \mathrm{~h}$ of stroke onset & $226(54.4)$ & $119(28.7)$ & $70(16.8)$ \\
\hline $\begin{array}{l}\text { Indicates that the benefits outweigh the risks if the treatment } \\
\text { protocol is followed }\end{array}$ & $134(32.3)$ & $107(25.8)$ & $173(42.0)$ \\
\hline Is strong enough to warrant the use of this treatment & $141(34.0)$ & $119(28.7)$ & $155(37.4)$ \\
\hline
\end{tabular}

Number of observations varies across items due to missing data.

${ }^{*} \mathrm{n}=415$. 


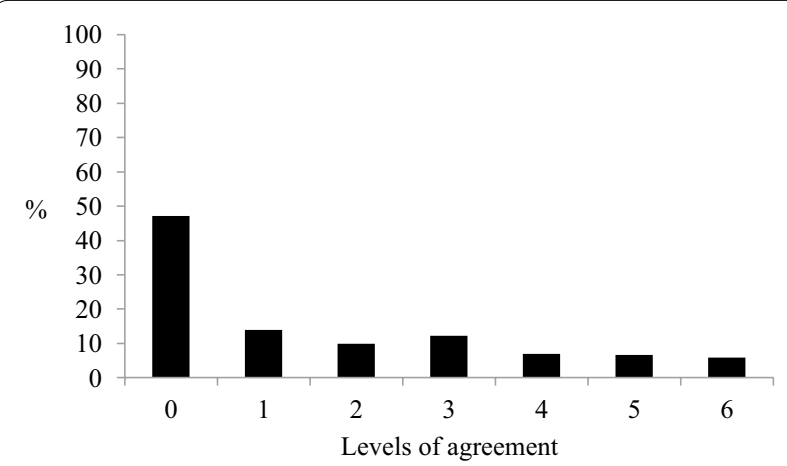

Figure 1 Emergency physicians' level of agreement with evidence for tPA use $(n=415)$.

evidence is strong enough to warrant use (37.4\%). This is despite approval from the Australian Therapeutic Goods Administration for tPA use, and recommendations in the current Australian clinical practice guidelines [5]. Use of tPA is also approved up to $4.5 \mathrm{~h}$ post-stroke onset in the UK by the Medicines and Healthcare Products Regulatory Agency, and recommended up to $4.5 \mathrm{~h}$ by AHA and ASA [15]. These results may be indicative of the influence of authoritative emergency-specific bodies that openly do not support the use of tPA by emergency physicians.

Previous studies have identified limited acceptance of the evidence for tPA use in acute stroke [17]. Scott's study of emergency physicians in the US found $49 \%$ agreed the science regarding the use of tPA in stroke is convincing [11]. Additionally, Wang reported $72 \%$ of responders recognised $\mathrm{tPA}$ is the preferred treatment for acute stroke, and 59\% were aware of the limited time-window for administration [16]. While Wang's outcomes may be biased due to the sampling procedure employed, and the inclusion of residents within family practice, internal medicine and neurology [16], these results highlight a lack of awareness regarding clinical practice guidelines for tPA use in acute stroke care.

Almost half of the respondents in our survey did not agree with any statements supporting tPA use in acute stroke, with only $20 \%$ of the respondents having "High agreement" with the literature. In order for tPA treatment to become widely accepted and adopted in emergency settings that have the necessary facilities, beliefs and attitudes towards treatment need to be in accordance with best-practice recommendations.

\section{Reasons behind physician views of tPA}

Research appears to be the key feature influencing attitudes of tPA. A high proportion of respondents reported 'additional clinical trials of tPA' (83.8\%), and 'research conducted by emergency department staff' (60.3\%) would influence their views. Indeed, there have been calls for additional clinical trials of tPA treatment to be conducted [18], leading to re-analysis of the National Institute of Neurological Disorders and Stroke trial data [19], and the spread of uncertainty towards use of this therapy [20]. However, given the existing evidence-practice gap, serious consideration about whether additional trials of tPA will actually shift attitudes and practice surrounding the use of tPA, is crucial in determining the next steps forward for the implementation of this therapy. While

Table 4 Individual factors associated with high agreement with the evidence for tPA use in acute stroke care

\begin{tabular}{|c|c|c|c|}
\hline Factors & Crude odds ratio $(95 \% \mathrm{Cl})$ & Adjusted odds ratio $(95 \% \mathrm{Cl})$ & Adjusted p-value \\
\hline Age & $1.01(0.98,1.04)$ & $1.06(0.99,1.13)$ & 0.09 \\
\hline \multicolumn{4}{|l|}{ Gender } \\
\hline Male & $1.21(0.69,2.12)$ & $0.96(0.48,1.92)$ & 0.91 \\
\hline \multicolumn{4}{|l|}{ Female } \\
\hline \multicolumn{4}{|l|}{ Role } \\
\hline Other vs Emergency physician trainee & $0.50(0.06,4.27)$ & $0.60(0.06,6.02)$ & 0.91 \\
\hline Emergency physician vs Emergency physician trainee & $0.91(0.53,1.55)$ & $0.92(0.32,2.65)$ & \\
\hline \multicolumn{4}{|l|}{ Years worked in emergency care } \\
\hline 5 years or less vs 16 years or more & $1.18(0.55,2.50)$ & $2.37(0.42,13.31)$ & 0.38 \\
\hline $6-10$ years vs 16 years or more & $0.94(0.48,1.87)$ & $1.92(0.47,7.85)$ & \\
\hline $11-15$ years vs 16 years or more & $1.27(0.66,2.44)$ & $2.30(0.90,5.92)$ & \\
\hline \multicolumn{4}{|c|}{ Does your role at the hospital include responsibility for determining the care that is provided to stroke patients? } \\
\hline Yes & $1.23(0.62,2.44)$ & $0.92(0.41,2.07)$ & 0.84 \\
\hline \multicolumn{4}{|l|}{ No } \\
\hline \multicolumn{4}{|c|}{ Does your role at the hospital include deciding which patients receive tPA? } \\
\hline Yes & $1.60(0.90,2.85)$ & $1.64(0.89,3.04)$ & 0.11 \\
\hline No & & & \\
\hline
\end{tabular}


Table 5 Workplace factors associated with high agreement with the evidence for tPA use in acute stroke care

\begin{tabular}{|c|c|c|c|}
\hline Factors & Crude odds ratio $(95 \% \mathrm{Cl})$ & Adjusted odds ratio $(95 \% \mathrm{Cl})$ & Adjusted p-value \\
\hline $\begin{array}{l}\text { How many ischaemic stroke patients are seen by the emergency } \\
\text { department every fortnight }\end{array}$ & $1.00(0.98,1.02)$ & $0.99(0.97,1.02)$ & 0.63 \\
\hline $\begin{array}{l}\text { The proportion that are referred to a stroke care unit or neurology } \\
\text { department }\end{array}$ & $1.00(0.99,1.00)$ & $0.99(0.98,1.00)$ & 0.28 \\
\hline $\begin{array}{l}\text { The proportion of ischaemic stroke patients who are currently treated } \\
\text { with thrombolysis at the hospital }\end{array}$ & $1.00(0.99,1.02)$ & $1.01(0.99,1.03)$ & 0.32 \\
\hline \multicolumn{4}{|c|}{ Does the hospital provide tPA treatment to eligible ischaemic stroke patients? } \\
\hline Yes & $1.08(0.58,2.00)$ & & \\
\hline \multicolumn{4}{|l|}{ No } \\
\hline \multicolumn{4}{|c|}{ Does the hospital have arrangements in place to receive pre-hospital notification of stroke patients from the ambulance service? } \\
\hline Yes & $1.19(0.69,2.06)$ & $1.02(0.48,2.18)$ & 0.95 \\
\hline \multicolumn{4}{|l|}{ No } \\
\hline \multicolumn{4}{|l|}{ Does the hospital have a dedicated Stroke Care Unit? } \\
\hline Yes & $1.02(0.57,1.84)$ & $0.72(0.25,2.03)$ & 0.53 \\
\hline \multicolumn{4}{|l|}{ No } \\
\hline \multicolumn{4}{|l|}{ Does the hospital have an Intensive Care Unit? } \\
\hline Yes & $0.78(0.28,2.23)$ & $2.46(0.24,24.87)$ & 0.45 \\
\hline \multicolumn{4}{|l|}{ No } \\
\hline \multicolumn{4}{|l|}{ Does the hospital have advanced imaging facilities (perfusion CT and MRI)? } \\
\hline Yes & $1.16(0.57,2.36)$ & $2.28(0.62,8.38)$ & 0.21 \\
\hline \multicolumn{4}{|l|}{ No } \\
\hline \multicolumn{4}{|c|}{ The proportion of the emergency physicians at your hospital who routinely administer tPA treatment for eligible ischaemic stroke patients } \\
\hline None & $0.63(0.35,1.13)$ & $0.96(0.43,2.11)$ & 0.91 \\
\hline \multicolumn{4}{|l|}{ Less than half/About half/Most/All } \\
\hline \multicolumn{4}{|c|}{ Does the head of emergency department routinely administer tPA treatment for eligible ischaemic stroke patients? } \\
\hline Yes & $4.05(1.88,8.72)$ & $3.87(1.49,10.04)$ & 0.01 \\
\hline \multicolumn{4}{|l|}{ No/l don't know } \\
\hline \multicolumn{4}{|l|}{ State } \\
\hline NSW vs TAS & $6.08(0.77,48.03)$ & & \\
\hline Vic vs TAS & $4.09(0.52,32.46)$ & & \\
\hline QLD vs TAS & $6.92(0.87,55.34)$ & & \\
\hline SA vs TAS & $4.50(0.45,44.55)$ & & \\
\hline WA vs TAS & $2.25(0.22,23.46)$ & & \\
\hline NT vs TAS & $0.00(0.00, I)$ & & \\
\hline ACT vs TAS & $10.80(0.91,127.75)$ & & \\
\hline
\end{tabular}

4th and 11th factors could not be included in the adjusted logistic regression model due to zero counts in some categories.

Scott's trial targeting hospital staff failed to produce a significant increase in use of tPA for stroke, the authors recognise that additional strategies to increase treatment are required [21].

\section{Factors associated with agreement with evidence for TPA}

Respondents were nearly four times more likely to have high agreement with the evidence supporting tPA use in acute stroke if they perceived their head of ED administers tPA treatment to eligible patients. This result is supported by the $43.8 \%$ of respondents who indicated guidance from a professional colleague would influence their views on the use of tPA. While no other studies have examined this relationship, one study found the presence of "uncompromising, individual clinical leadership" in a hospital setting was significantly associated with the likelihood of receiving tPA [22]. Results are indicative of the power of social influence and modelling in changing health providers' attitudes and behaviour [23]. Social influences play an important role in the implementation of new behaviours, and by targeting provider knowledge, attitudes and social norms, opinion leaders can aid adoption of new practices [24]. Demonstrating or modelling new skills, can build both skill and confidence to perform 
a desired behaviour [25]. Local opinion leaders in hospital settings can also be effective in promoting evidencebased practice [23].

\section{Limitations}

The study yielded a low response rate (13\%), limiting the generalizability of the sample and power of the study. It is possible that only individuals with a strong opinion about tPA use responded. However, low response rates among health-care providers is common and our results are not dissimilar to other online surveys of physicians [26-29]. Hospital characteristics were obtained via self-report and therefore may not be accurate. Hospital location was not obtained, therefore it is not clear how representative results are of physicians working in urban vs rural hospitals.

The survey did not measure respondents' knowledge of guidelines or criteria for tPA use in stroke, or whether individual physicians had previously administered or were likely to administer tPA. These items may have been associated with high agreement with evidence supporting tPA use as previous use of tPA for stroke is independently associated with a willingness to use tPA [10]. Future studies should measure these constructs. While it is acknowledged that there is conflicting evidence on the use of tPA for acute stroke, the study was specifically designed to assess perceptions on the use of, and evidence supporting, tPA. The terms 'appropriate' and 'treatment protocol' were used in a number of survey items, assuming a shared meaning of being in accordance with clinical practice guidelines [5]. In addition, as administration of tPA within $6 \mathrm{~h}$ of stroke onset significantly increases the odds of being alive and independent at follow-up [4], the term 'save lives' was intended to refer to an improvement in quality of life and DALYs, rather than a reduction in mortality. However, as these terms, along with the word 'unnecessary', were not defined within the survey, interpretation may differ among respondents.

Finally, $345 \mathrm{NZ}$ fellows and trainees within ACEM were accidently sent the invitation email by ACEM. Although the total number of NZ members has not been included in the denominator, results may contain a number of NZ responders (estimated maximum of $1.4 \%$ of responders). The invitation to NZ members was rescinded immediately and is unlikely to have influenced results.

\section{Conclusions}

This was the first study to examine rates of agreement with evidence supporting tPA use in acute stroke care, as well as the individual and hospital factors associated with agreement with the evidence among Australian emergency physicians. Our results correspond with previous international literature, finding low rates of agreement with particular published literature on the potential benefits of tPA use among responding emergency physicians.

Study results demonstrate that attitudes among emergency health-care providers may in fact be one of the factors limiting tPA administration rates. Agreement with clinical practice guidelines for stroke is likely to be necessary if tPA treatment is to become widely adopted in hospitals possessing the appropriate facilities. Future research should explore strategies to increase participation in research among specialist physicians to overcome low response rates and increase the generalisability of study findings. In addition, examination of the effectiveness of health-provider targeted interventions with a focus on social influence and modelling to increase physician agreement with clinical practice guidelines is an area in need of further research. Our findings that the opinions and actions of ED heads and professional colleagues influence emergency physicians' views may be valuable information to clinical leaders and shape their practice in ensuring health-care provider adherence to clinical guidelines.

Emergency physicians' perceptions represent a potentially modifiable barrier to the use of tPA treatment. An increase in emergency physician agreement with the literature regarding tPA use in acute stroke may have the potential to produce substantial benefits for stroke patients.

\section{Availability of supporting data}

The data set supporting the results of this article is included within the article and its additional file.

\section{Additional file}

Additional file 1: Perceptions of the use of tissue Plasminogen Activator (tPA) in acute stroke care among emergency physicians.

\section{Abbreviations}

AHA: American Heart Association; ASA: American Stroke Association; ACEM: Australasian College for Emergency Medicine; ACT: Australian Capital Territory; DALYs: Disability-adjusted life years; ED: Emergency Department; F.A.S.T: Face, Arm, Speech, Time; ICU: Intensive Care Unit; NSF: National Stroke Foundation; NSW: New South Wales; NZ: New Zealand; NT: Northern Territory; QLD: Queensland; SA: South Australia; SCU: Stroke Care Unit; TAS: Tasmania; TPA: tissue Plasminogen Activator; UK: United Kingdom; US: United States; VIC: Victoria; WA: Western Australia.

\section{Authors' contributions}

AG contributed to the design of the study, managed data acquisition, analysis and interpretation, and drafted the manuscript. JB contributed to the study design, provided interpretation of the data, and helped in drafting the manuscript and its critical revision. MC was involved in the conception and design of the study, contributed to the interpretation of data, and the critical revision of the manuscript. CP contributed to the study design, and was involved in the interpretation of data and critical revision of the manuscript. RSF conceived and designed the study, contributed to the interpretation of data, and was involved in the critical revision of the manuscript. CL was involved in the conception of the study, the interpretation of data, and the critical revision of the manuscript. All authors read and approved the final manuscript. 


\section{Author details}

${ }^{1}$ Priority Research Centre for Health Behaviour, Hunter Medical Research Institute (HMRI), University of Newcastle, Callaghan, NSW 2308, Australia. ${ }^{2}$ Department of Neurology, John Hunter Hospital, New Lambton, NSW 2305, Australia. ${ }^{3}$ Priority Research Centre for Translational Neuroscience and Mental Health, University of Newcastle, Callaghan, NSW 2308, Australia.

\section{Acknowledgements}

We would like to thank Zoe Cocks from the ACEM for her assistance in survey dissemination, and Alessandra Bisquera from HMRI for her assistance with data analysis.

\section{Compliance with ethical guidelines}

\section{Competing interests}

Christine Paul, Rob Sanson-Fisher and Christopher Levi have received a financial contribution from Boehringer Ingelheim towards an NHMRC-funded trial. Christopher Levi has received consultancy fees from Boehringer Ingelheim and is a member of the Clinical Council of the National Stroke Foundation. Alice Grady, Jamie Bryant and Mariko Carey have no competing interests to declare.

Received: 17 March 2015 Accepted: 17 June 2015

Published online: 26 June 2015

\section{References}

1. Murray CJ, Vos T, Lozano R, Naghavi M, Flaxman AD, Michaud C et al (2013) Disability-adjusted life years (DALYs) for 291 diseases and injuries in 21 regions, 1990-2010: a systematic analysis for the global burden of disease study 2010. Lancet 380:2197-2223

2. Wahlgren N, Ahmed N, Davalos A, Ford GA, Grond M, Hacke W et al (2007) Thrombolysis with alteplase for acute ischaemic stroke in the safe implementation of thrombolysis in stroke-monitoring study (SITSMOST): an observational study [Erratum appears in Lancet. 2007 Mar 10;369(9564):826]. Lancet. 369:275-282

3. Fagan SC, Morgenstern LB, Petitta A, Ward RE, Tilley BC, Marler JR et al (1998) Cost-effectiveness of tissue plasminogen activator for acute ischemic stroke. NINDS rt-PA Stroke Study Group. Neurology 50:883-890

4. Wardlaw JM, Murray V, Berge E, del Zoppo G, Sandercock P, Lindley RL et al (2012) Recombinant tissue plasminogen activator for acute ischaemic stroke: an updated systematic review and meta-analysis. Lancet 379:2364-2372

5. National Stroke Foundation (2010) Clinical guidelines for stroke management. National Stroke Foundation, Melbourne

6. National Stroke Foundation (2013) National stroke audit acute servicesorganisational survey report. National Stroke Foundation, Melbourne

7. National Stroke Foundation (2013) National stroke audit-acute services clinical audit report. National Stroke Foundation, Melbourne

8. Party Intercollegiate Stroke Working (2011) National sentinel stroke audit 2010 round 7. Royal College of Physicians of London, London

9. Fang MC, Cutler DM, Rosen AB (2010) Trends in thrombolytic use for ischemic stroke in the United States. J Hosp Med 5:406-409

10. Brown DL, Barsan WG, Lisabeth LD, Gallery ME, Morgenstern LB, Brown DL et al (2005) Survey of emergency physicians about recombinant tissue plasminogen activator for acute ischemic stroke. Ann Emerg Med 46:56-60

11. Scott PA, Xu Z, Meurer WJ, Frederiksen SM, Haan MN, Westfall MW et al (2010) Attitudes and beliefs of Michigan emergency physicians toward tissue plasminogen activator use in stroke: baseline survey results from the increasing stroke treatment through interactive behavioral change tactic (INSTINCT) trial hospitals. Stroke 41:2026-2032
12. Somerfield J, Barber P, Anderson N, Spriggs D, Charleston A, Bennett $P$ (2006) Changing attitudes to the management of ischaemic stroke between 1997 and 2004: a survey of New Zealand physicians. Intern Med J. $36: 276-280$

13. Grady A, Bryant J, Carey M, Paul C, Sanson-Fisher R (2014) Enablers of the implementation of tissue Plasminogen Activator in acute stroke care: a cross-sectional survey. PLoS One 9:e114778

14. Dewey HM, Churilov L, Blacker D, Bladin C, Davis SM, Donnan GA et al (2010) Response to "A graphic reanalysis of the NINDS trial". Ann Emerg Med 55:227-229

15. Jauch ECSJ, Adams HP Jr, Bruno A, Connors JJ, Demaerschalk BM, Khatri P et al (2013) Guidelines for the early management of patients with acute ischemic stroke: a guideline for healthcare professionals from the American Heart Association/American Stroke Association. Stroke 44:870-947

16. Wang MY, Lavine SD, Soukiasian H, Tabrizi R, Levy ML, Giannotta SL (2001) Treating stroke as a medical emergency: a survey of resident physicians' attitudes toward "brain attack" and carotid endarterectomy. Neurosurgery. 48:1109-1115 discussion 1115-1107

17. Meurer WJ, Majersik JJ, Frederiksen SM, Kade AM, Sandretto AM, Scott PA (2011) Provider perceptions of barriers to the emergency use of tPA for acute ischemic stroke: a qualitative study. BMC Emerg Med 11:5

18. Wardlaw J, Sandercock P, Berge E (2003) Thrombolytic therapy with recombinant tissue Plasminogen Activator for Acute ischemic stroke where do we go from here? A Cumulative Meta-Analysis. Stroke 34:1437-1442

19. Ingall TJ, O'Fallon WM, Asplund K, Goldfrank LR, Hertzberg VS, Louis TA et al (2004) Findings from the reanalysis of the NINDS tissue plasminogen activator for acute ischemic stroke treatment trial. Stroke 35:2418-2424

20. Zivin JA, Simmons JG (2010) tPA for stroke: the story of a controversial drug. Oxford University Press, New York

21. Scott PA, Meurer WJ, Frederiksen SM, Kalbfleisch JD, Xu Z, Haan MN et al (2013) A multilevel intervention to increase community hospital use of alteplase for acute stroke (INSTINCT): a cluster-randomised controlled trial. Lancet Neurol 12:139-148

22. van Wijngaarden JDH, Dirks M, Huijsman R, Niessen LW, Fabbricotti IN, Dippel DWJ et al (2009) Hospital rates of thrombolysis for acute ischemic stroke: the influence of organizational culture. Stroke 40:3390-3392

23. Flodgren G, Parmelli E, Doumit G, Gattellari M, O'Brien MA, Grimshaw J et al (2011) Local opinion leaders: effects on professional practice and health care outcomes. Cochrane Db Syst Rev 8:CD000125. doi:10.1002/14651858.CD000125.pub4

24. Azjen I (1985) From intentions to actions: a theory of planned behaviour In: Kuhl J, Beckman J (eds) Action-control: from cognition to behaviour. Springer, Heidelberg, pp 11-39

25. Bandura A (1986) Social foundations of thought and action. Prentice-Hall, Englewood Cliffs

26. Einav S, Alon G, Kaufman N, Braunstein R, Carmel S, Varon J et al (2011) To resuscitate or not to resuscitate: a logistic regression analysis of physicianrelated variables influencing the decision. Emerg Med J. doi:10.1136/ emermed-2011-200206

27. Braithwaite D, Emery J, De Lusignan S, Sutton S (2003) Using the Internet to conduct surveys of health professionals: a valid alternative? Fam Pract 20:545-551

28. Marmor GO, Braitberg G, Nicolas CM (2011) Medication prescribing, surveillance and safety in Australasian emergency departments. J Pharm Pract Res 41:113

29. Grady A, Carey M, Bryant J, Sanson-Fisher R (2014) Recruitment of healthcare specialists. Emerg Med Australas. doi:10.1111/1742-6723.12275 